\title{
Phase II investigation of a PARP inhibitor (olaparib) in castration resistant prostate cancer (CRPC) which incorporates the possibility that treatment effect may be restricted to biomarker defined subgroups
}

\author{
Roger A'Hern ${ }^{*}$, Johann DeBono ${ }^{2}$, Shahneen Sandhu², Eletheria Kalaitzaki ${ }^{1}$, Martine Usdin ${ }^{1}$ Emma E Hall ${ }^{1}$
}

From Clinical Trials Methodology Conference 2011

Bristol, UK. 4-5 October 2011

\section{Objective}

To undertake a phase II trial to identify the best CRPC patient group(s) to be studied for sensitivity to olaparib in a randomised, controlled phase III trial.

\section{Methods}

The TO-PARP trial has a multistage phase II design consisting of a non-randomised component with response as the primary endpoint followed by a randomised component with overall survival as the primary endpoint.

Non-randomised component: This part of the trial design allows rapid progression to a randomised comparison if there is evidence of a high response rate $(50 \%$ or more) in unselected patients. If the evidence for a high response rate in unselected patients is weak, biomarker defined groups will be investigated for their sensitivity to olaparib.

The first stage will include 30 CRPC patients. If 15 $(50 \%)$ or more respond then no more patients will be entered and the randomised component will be undertaken in unselected patients. Should 2 (7\%) or fewer respond then olaparib will be rejected. If between 3-14 (10\%-47\%) patients respond then a further 15 patients will be entered. Should 23 (51\%) or more respond overall then the randomised component will be undertaken in unselected patients and if $5(11 \%)$ or fewer respond then olaparib will be rejected. Otherwise with 6-22 responders (13\%-49\%), biomarker analysis of tissue collected from all 45 patients will be undertaken. This will aim to identify a sensitive subgroup, with a response rate which is compatible with a $50 \%$ response rate, warranting further assessment in the randomised component. If such a subgroup is found, a confirmatory single stage 44 patient trial will be undertaken in this subgroup; this will also serve to pilot prospective biomarker testing in a multi-centre clinical trial setting.

Randomised component : This is a phase II controlled, definitive endpoint assessment of the results generated in the non-randomised part, offering a more secure foundation for efficacy before proceeding to phase III. 180 patients will be randomised 2:1 to olaparib or an appropriate standard of care ( $\alpha 1$-sided $10 \%$, power $80 \%)$.

\section{Conclusions}

Randomised phase II trials are the gold standard to establish a basis for treatment efficacy but only a subset of patients may be sensitive to a new therapy. This possibility was incorporated into the design of the TOPARP trial by introducing a non-randomised initial component with the potential to identify a sensitive subgroup. 


\section{Author details}

${ }^{1}$ Clinical Trials and Statistics Unit, Institute of Cancer Research, Sutton, Surrey,

SM2 5NG, UK. ${ }^{2}$ Department of Experimental Cancer Medicine, Institute of

Cancer Research, Sutton, Surrey, SM2 5NG, UK.

Published: 13 December 2011

doi:10.1186/1745-6215-12-S1-A88

Cite this article as: $A^{\prime}$ Hern et al:: Phase II investigation of a PARP

inhibitor (olaparib) in castration resistant prostate cancer (CRPC) which

incorporates the possibility that treatment effect may be restricted to

biomarker defined subgroups. Trials 2011 12(Suppl 1):A88.

Submit your next manuscript to BioMed Central and take full advantage of:

- Convenient online submission

- Thorough peer review

- No space constraints or color figure charges

- Immediate publication on acceptance

- Inclusion in PubMed, CAS, Scopus and Google Scholar

- Research which is freely available for redistribution

Submit your manuscript at 